\title{
Developing a Vocational Training Computer Game Workplace Simulator: The Vocational Game Project
}

\begin{tabular}{|c|c|c|}
\hline Mark O'Rourke & Tas Papasimeon & Juanita Custance \\
Victoria University & Victoria University & POniversity \\
PO Box 14428 & PO Box 14428 14428 \\
Melbourne VIC 8001 Australia & Melbourne VIC 8001 Australia & Melbourne VIC 8001 Australia \\
6139919 1587 & 61399191587 & 61383070083 \\
mark.orourke@vu.edu.au & tas.papasimeon@vu.edu.au & juanita.custance@vu.edu.au \\
\hline
\end{tabular}

\section{Abstract}

This study presents the research and production processes for the development of a Vocational Training computer game workplace simulator that will be used to deliver competency-based training of Occupational Health and Safety and planning competencies in the Engineering sector. The project is a collaboration between the Centre for Vocational \& Workbased Research in the Faculty of Technical and Trade Innovation, and the School of Creative Industries at Victoria University, Melbourne, Australia.

The study focuses on the design and development of immersive educational environments and assesses the optimal level of interactivity and game play necessary to achieve identified learning outcomes.

This application of games technologies and the development of immersive learning environments enables the targeted delivery of flexible, customised learning programs in the workplace ensuring participant engagement through active learning.

\section{Keywords}

vocational; training; game; simulation; development; immersive

\section{Introduction}

The Vocational Game Project addresses curriculum material for the units of study:

- MEM13014A: Apply principles of occupational health and safety in the work environment

- MEM14004A Plan to undertake a routine task

- MEM14005A Plan a complete activity

from MEM05 Metal and Engineering Training Package. A Training Package is a set of Australian nationally endorsed standards and qualifications used to recognise and assess the skills and knowledge required to perform effectively in the workplace. The units are currently delivered in booklet form, which students work through independently. These particular units have been selected for The Vocational Game Project because competency in Occupational Health and Safety (OHS) and planning is fundamental to the successful sustainability of an engineering workforce, however allowing trainees to gain real world experience on industrial equipment presents industry and training institutes with resource and logistic difficulties, while exposing personnel to potential risk. Multi-user computer-based simulator games are well suited 
to delivering this training because the interactive game environment engages participants by making them active agents in the learning experience, and offers a virtual reality that supplies rewards and builds expertise, yet provides a safe place in which to learn and explore.

\section{Background}

Multi-user computer games tend to be used and perceived as a recreational pastime, but have a largely unrealised potential to become incredibly effective tools in which to engage a broad range of learners.

The acquisition of any skill base is achieved by participating in activities and articulating ways of learning through which knowledge is developed, defended, and modified. Intrinsically, gameplay has these same characteristics. Computer games have the capacity to become important learning systems because they engage participants by making them active agents in their own learning rather than passive consumers of received knowledge. Game players adopt and invest in new identities through gameplay, thus allowing learners to take risks and imagine themselves in the roles they are training to achieve. Optimum learning that is deep and enduring is more readily achieved when delivered within relevant contexts of both identity and activity. The virtual learning environment provides learners with a system of essential variables and interactions that can easily become obscured in real world situations. In the context of the Vocational Game Project, it should be noted that the virtual environment in no way replaces real world experience, but rather supplies an entrée to it.

The game space cultivates:

- a more intense and broadly based affinity group - bonded through shared endeavour, goals, and practices and not through shared race, gender, ethnicity or culture identities;

- the leveraging of knowledge from other people and from various tools and technologies; and

- the fostering of networks with multi-layered forms of communication[1].

Games have the capacity to engage learners in activities that involve interacting with a variety of social, psychological and physical channels. Process-driven pedagogical systems based on experiential learning provide a more durable model of skills acquisition than content-driven systems, which tend to promote surface learning with learners recalling facts in isolation. The activity generated by process-driven systems creates deep learning environments in which key content elements become placed within existing conceptual structures and which provide learners with more durable and transferable knowledge and skills. Research[2] indicates that better learning outcomes in computer-aided learning (CAL) can be achieved by designing products that require users to apply increased cognitive resources to acquiring information through gameplay within a narrative framework than through that achieved by an overt focus on the target content. The data indicated that optimum deep learning is accessed when CAL learners engage with content in a games-based narrative context. It is these findings that inform the development of the Vocational Training Game being produced. This Vocational Game will 
deliver content, foster communication, engage participants and address defined pedagogical requirements through computer gameplay as core elements of the game's system.

The Vocational Game scenario will take place in an Engineering workshop where the user will play the role of a new employee. The user will make a series of planning and safety-based choices relating to uniform, protective clothing, handling chemicals, operating machinery and performing tasks. The user will interact with supervisors and fellow workers, with the game goal being to successfully plan and perform a day's work without injuring themselves, their fellow workers or destroying equipment. The competency requirement is for learners to be aware of their actions in mitigating risk.

The associated study will include an assessment of the impact of fun and the impact of narrative on learning outcomes when computer games are used for Vocational Training. 'Fun' and 'narrative' are two potential elements of process systems that have the capacity to be utilised in Computer Game-based training. Our research to date has included the evaluation of 'narrative' as a component of the learning system. The decision to include the criteria of fun in exploring the relationship between deep learning and narrative is the result of observations made during qualitative data collection of previous projects.

\section{Key Assumptions}

\section{(a) Activity Systems}

When using game-based products players concentrate their cognitive resources on game moves rather than content[3]. Does this user-focus on strategic gameplay effect learning outcomes? In order to investigate this question an activity framework will be adopted as both an analytic tool for evaluating complex Human Computer Interaction $(\mathrm{HCl})$ systems[4] and as a learning system that takes account of the interactions between the various contradictory forces that produce learning outcomes[5][6].

Activity Theory provides a theoretical language for analysing the learning outcomes of educational games. The Theory illustrates how the effectiveness of any learning system is dependant upon the interplay of subjects and objects[5][7](Figure 1). Game players can be perceived as subjects, and the game world that they interact with, make decisions and effect changes in, is the objective cultural-specific environment. An Activity System allows for the interactions and consequent transformations of personal, social, cultural and technical elements within its boundaries[6]. It represents the processes of learning as developmental transformations in the Vgotsykian tradition, occurring through the interaction of contradictory variables within a dynamic system. This interplay of contradictions creates developmental transformations, which, in this case, are understood as learning outcomes. Activity Systems are capable of continual transformations, because any component's development will impact on the behaviour of other system components[8]. 
Figure 1

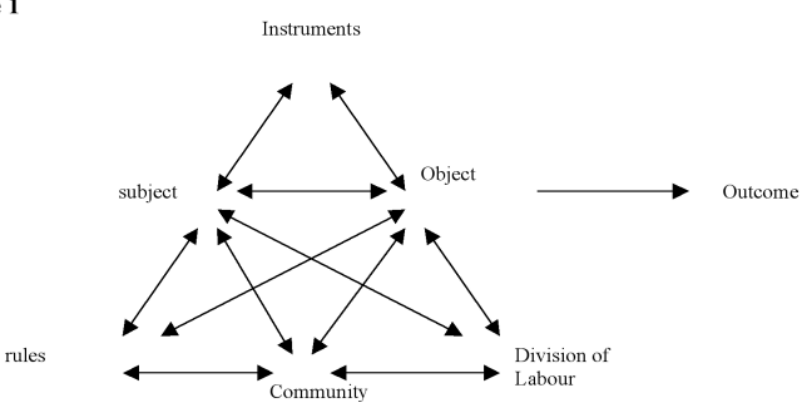

Figure 1: ACTIVITY SYSTEM Based On Engestrom's Expanded Triangulation Of Activity

Activity theory also utilizes the concept of the Zone of Proximal Development (ZPD)[9], where the acquisition of new knowledge is dependant on its contextualisation with previous understandings and is scaffolded on pre-existing skills mediated by interaction with a tutor.

Computer-aided learners must have an appropriate level of technical knowledge, as well as existing disciplinary and socio-cultural understandings in order to develop their learning. As existing skills are required to scaffold new knowledge, learners and educators need to be games-literate in order for the delivery of learning activities via computer gameplay to be effective(Figure 2). Part of the difficulty games-based educational products face in gaining acceptance is that the semantics, as well as the tools and actions, of gameplay can be unclear to the uninitiated. Educational developers, more skilled in traditional literacies, have accordingly marginalised narrative-based computer game activities as 'timewasters' and playthings.

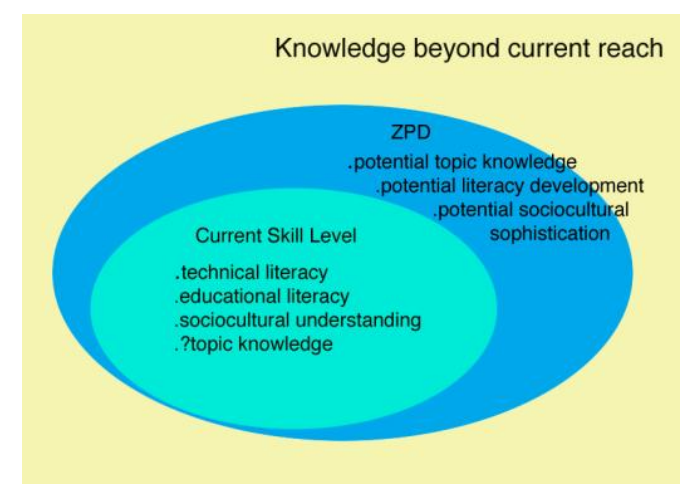

Figure 2: ZPD Factors To Be Considered In The Design Of Educational Computer Games

\section{(b) Deep Learning}

The rapid pace of technological and social change means that learners can no longer assume that specific skills will remain current. Learners must become capable of finding solutions to problems they have never encountered before. 
Deep learning is that which provides access to a series of skills and methods that equip learners to become effective problem solvers and information researchers, allowing knowledge to be adapted in new situations.

The activity generated by process-driven systems creates deep learning environments in which key content elements can be placed within existing conceptual structures. This provides for a more durable system of knowledge than content-driven systems that promote surface learning, where learners tend to recall facts in isolation[10].

In process-driven learning the subject's immersion in the Activity System creates deep, sustainable learning. Deep learning is accessed through engaging in activity that involves interacting with a variety of social, psychological and physical channels. The system is transformed by the knowledge that the learner brings to it, even as the learner is transformed by interacting within the system.

Squire's[6] conceptualised the Activity System as one where subjects' interactions with physical or abstract objects are mediated by both tools (such as concepts or resources) and cultural context, and occur within communities with whom the subject both shares transformation of the object and mediates activity through division of labour and shared norms and expectations (such as tutorial groups or workplaces). The distinctions between sustainable process-driven systems and short-term content-dependent learning become apparent when learning methods and outcomes are evaluated in this way.

\section{(c) Narrative Games and Educational Products}

Although computer games are categorised as goal-orientated[11], winning is often secondary to gameplay, especially when moves are used as a way of exploring story. Game moves create narrative as much as the choice of a particular move is determined by the narrative's demands. Gameplay and narrative become components of the same semantic system. Gameplay moves with all their strategic and socio-cultural implications, become another component of the language through which narrative is constructed[3] and can be undertaken as an interpretive as well as a configurative practice.

In entertainment games the constrained set of moves the player chooses from at any particular point of game play are commonly used for narrative purposes as well as providing player manoeuvrability. However, very few educational games contain this level of narrative sophistication.

Lindley[3] identifies three game system semiotics: simulation, game, and narrative. Typically, education products have focussed on the game and some simulation elements. Anecdotal evidence suggests this is because educational developers believe learners might otherwise become lost in the narrative, concentrating their gameplay on achieving narrative-driven goals rather than on achieving the intended learning outcomes. Our earlier research tested this assumption by assessing competency outcomes achieved through narrative gameplay and comparing it with competency results from more conventional CAL delivery. The initial results of these small-scale studies have encouraged us to further explore the possibilities of narrative gameplay-based CAL for Vocational Education. 


\section{Aims and Methodology}

The aim of the Vocational Game Project is to develop a Vocational Training computer game to deliver competency-based training for Units of Study MEM13014A, MEM14004A and MEM14005A from the Training Package MEM05 Metal and Engineering Training Package.

Vocational training in Engineering fundamentally employs a hands-on approach involving a community of experts (trainers and curriculum) and apprentices. The Vocational Game will take place in a simulated Engineering workshop and involve the user in a first person experience undertaking tasks, roles and duties in accordance with the MEM05 Metal and Engineering Training Package planning and occupational health and safety requirements.

The Vocational Game Project will proceed via a 6 phase pedagogically-focussed development and evaluation process[12] and a final evaluative and developmental review phase: This approach, as detailed below, with its focus on user needs and training requirements, is particularly suited to the development of this project.

1. Analyse the training domain

The training domain for this project is largely defined by the Training Package (curriculum) a set of Australian nationally endorsed standards and qualifications aligned to the Australian Qualifications Framework (AQF), which prescribes:

- performance criteria,

- underpinning skills and knowledge,

- critical aspects of evidence, and

- method and context of assessment.

The assessment and delivery criteria from the Units of Competency MEM13014A, MEM14004A and MEM14005A will be contextualised for the training domain by interviewing trainers and students about their experiences of the delivery of the units of study, collecting anecdotal evidence in consultation with the Engineering industry sector, and by viewing video footage of training scenarios.

2. Develop a story board prototype

Under direction of the Production Management team and in consultation with the Curriculum team, the Game Design team (creative) will develop a written game play scenario and visual storyboards. Pedagogical controls such as feedback mechanisms, a scoring system, and game inventory needs will inform the design. The inventory will include, but is not limited to, game resources such as safety information and equipment, how and when this data/equipment is acquired, and the system response to users unsuccessfully attempting game moves.

3. Implement a computer version of the training prototype

The Production Management team will select a suitable game engine, from which the Game Design team (programming) will build the game world environment. The Game Design team (creative) will design and model the user interface and graphic elements.

4. Refine training objectives and link their conditions and standards to game activities. 
Once working versions of the system are available, usability testing will be conducted by the Production Management team. The process of usability testing will be guided by the need to ascertain the optimal level of interactivity and game play necessary to achieve competency in the Units of Study including assessments of:

- Learnability (e.g. intuitive navigation)

- Efficiency of use

- Memorability

- Few and non-catastrophic errors

- Subjective satisfaction.

The Production Management team will ensure the game system maintains a continuous assessment functionality by recording players' progress and scores. The Curriculum team will review game actions to ensure their alignment with learning outcomes.

5. Develop training support content for students, instructors and training developers.

The Curriculum team will oversee the development of supportive learning materials and gameplay instructions for teachers and students. Supportive material for teachers will include activities on how to use the training game to promote discussion and learning in a classroom environment or as part of a flexible learning package. Data for the development of these activities will be, in part, collected by observation and interview of teachers currently using multimedia and activity-based learning as part of their tutorial repertoire.

6. Evaluate pedagogical outcomes of game and review development process

The Project management team will oversee an evaluative Action Research survey utilising Activity theory in order to assess the pedagogical outcomes of the vocational game and assess how the variable components, with particular consideration of the subject's enjoyment (fun) and narrative, both interact with, and manifest as, learning outcomes (Figure 4).

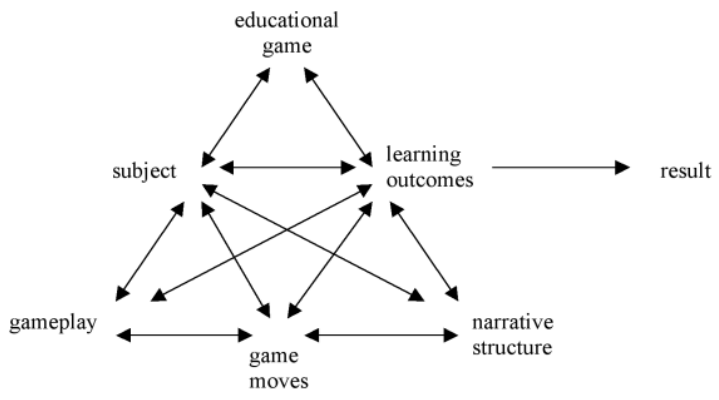

Figure 4: ACTIVITY SYSTEM for Vocational Game Project

An Activity Checklist[13] will be used to guide the activity-focussed data generation phase and in subsequent analysis, with key attention to:

- The structure of the user's activities - how the gameplay facilitates /constrains successful learning outcomes; 
- The structure of environment - integration of game design with narrative elements, gameplay and game moves;

- The structure and dynamics of interaction -interaction with the information and transformation through the game to knowledge gained; and

- Developmental transformation of components as a whole

The project management team will conduct a review and assessment of the 6 phased development process, identifying in particular any areas of communication breakdown, and making recommendations on a preferred structure of developmental models for collaborative projects.

\section{Production Design}

The project will constitute the following teams:

A. Project Management Team -2 staff

B. Curriculum Team -2 staff + teachers in Engineering Program

C. Production Management Team -2 staff

D. Game Design Team - 4 staff

(i) Programming

(ii) Creative

Table 1: Project Phases

\begin{tabular}{|c|c|c|c|}
\hline PHASE & TASKS & TEAM & COMPLETION \\
\hline \multirow[t]{4}{*}{$\begin{array}{l}\text { Phase 1: } \\
\text { Analyse the Training Domain }\end{array}$} & $\begin{array}{l}\text { training package/units of competency } \\
\text { addressed }\end{array}$ & B & March 2008 \\
\hline & gameplay usability assessed & C & June 2008 \\
\hline & $\begin{array}{l}\text { assessment evidence/skill levels } \\
\text { alignment with game goals }\end{array}$ & $B \& C$ & March 2008 \\
\hline & interview teachers and students & B & April 2008 \\
\hline \multirow{6}{*}{$\begin{array}{l}\text { Phase 2: } \\
\text { Develop the Storyboard Prototype }\end{array}$} & character/story development & $\mathrm{C}$ & April 2008 \\
\hline & student developers briefed & $B \& C$ & March 2008 \\
\hline & world design & $C \& D(i i)$ & May 2008 \\
\hline & script writing & $C \& D(i i)$ & April 2008 \\
\hline & storyboarding & $C \& D(i i)$ & April 2008 \\
\hline & pedagogical controls & $B \& C$ & April 2008 \\
\hline \multirow{5}{*}{$\begin{array}{l}\text { Phase 3: } \\
\text { Implement a computer version of the } \\
\text { training prototype }\end{array}$} & game engine choice & $\mathrm{C}$ & April 2008 \\
\hline & $\begin{array}{l}\text { character/object modelling and } \\
\text { animation, }\end{array}$ & $\mathrm{D}$ (ii) & June 2008 \\
\hline & world layout, & $\mathrm{D}$ (ii) & June 2008 \\
\hline & audio & $\mathrm{D}$ (ii) & June 2008 \\
\hline & programming & $\mathrm{D}$ (i) & June 2008 \\
\hline \multirow{2}{*}{$\begin{array}{l}\text { Phase 4: } \\
\text { Refine training objectives \& link their } \\
\text { conditions \& standards to game } \\
\text { activities }\end{array}$} & playability \& usability testing & C & August 2008 \\
\hline & $\begin{array}{l}\text { learning outcomes aligned to game } \\
\text { actions }\end{array}$ & B \& C & August 2008 \\
\hline \multirow{2}{*}{$\begin{array}{l}\text { Phase 5: } \\
\text { Develop training support content for } \\
\text { students, instructors \& training } \\
\text { developers }\end{array}$} & $\begin{array}{l}\text { learning materials developed for } \\
\text { students }\end{array}$ & $A \& C$ & September 2008 \\
\hline & directions for teachers & $A \& C$ & September 2008 \\
\hline \multirow{3}{*}{$\begin{array}{l}\text { Phase 6: } \\
\text { Evaluate pedagogical outcomes of } \\
\text { game \& review development process }\end{array}$} & $\begin{array}{l}\text { learning outcomes review } \\
\text { andassessment }\end{array}$ & $A \& B$ & October 2008 \\
\hline & action research survey & A & October 2008 \\
\hline & review of development process & A & October 2008 \\
\hline
\end{tabular}




\section{Conclusion}

The Vocational Game Project will provide a highly responsive, immersive learning environment addressing key competencies in engineering pedagogy. It is hoped that introduction of the game will ease some of the teaching and learning constraints currently experienced in traditional teaching and learning methodologies, and that the development process and assessments undertaken by the project teams will lead to further applications of gameplay in simulated environments addressing curriculum needs of other trades and industries.

The success of the Vocational Game Project is largely dependant upon ensuring that its developmental process is structured in such a way that it allows for effective collaboration across pedagogical, technical, industry, and creative stakeholders, and that the completed game product has been developed with an acute awareness of actual student behaviour and current gameplay theory.

Evaluation of the Vocational Game Project will consider two project components. The first will evaluate learning outcomes by trialling the game with the targeted student cohort and their trainers. The pedagogical structure will be evaluated by quantitatively assessing student competency in the Units of Competency MEM13014A, MEM14004A and MEM14005A, and qualitatively by interviewing and observing students and teachers. The second will reflect on the Project's developmental process and consider the need for refinements to the developmental phases, with a focus on enhancing the environment for collaborative partnerships across pedagogical, creative, and industry domains.

\section{References}

[1] Gee, P G, 2003. What Video Games have to Teach us about Learning and Literacy. Palgrave Macmillan, New York. pp.192193

[2] O’Rourke, M. \& Custance, J. (Forthcoming paper) 'The Role of Narrative in Learning Through Computer Gameplay'

[3] Lindley, C 2005 'The Semiotics of Time Structure in Ludic Space As a Foundation for Analysis and Design' Game Studies: the international journal of computer game research vol 5 issue 1 viewed Nov 2006 http://www.gamestudies.org/0501/lindley/

[4] Engestrom, Y, 2000 'Activity Theory As A Framework For Analyzing And Redesigning Work' Ergonomics, Vol. 43, No. 7, pp. 960-974

[5] Engestrom, Y. 1993. 'Developmental studies of work as a testbench of activity theory: The case of primary care medical practice'. In Chaiklin S\& Lave J(Eds.) Understanding practice: Perspectives on activity and context pp. 64-103.: CUP. Cambridge, MA

[6] Squire, K, 2002 Cultural Framing of Computer/Video Games. The international Journal of Computer Games Research Vol2, Issue 1 , viewed Nov 2006, < http://www.gamestudies.org/0102/squire/>

[7] Leont'ev, A. N. 1978 Activity. Consciousness. Personality. Prentice Hall Englewood Cliffs, NJ

[8] Kaptelinin, V and Cole, M 2002 Individual and Collective Activities in Educational Computer Game Playing viewed Nov 2006 http://lchc.ucsd.edu/People/MCole/Activities.html

[9] Vygotsky, L.S 1978, Mind in Society: The Development of Higher Psychological Processes : Harvard University Press Cambridge MA

[10] Biggs, J. 1999. Teaching for Quality Learning at University: SRHE and Open University Press Buckingham.

[11] Eskelinen, M. 2001 'The Gaming Situation'. The International Journal of Computer Games Research Vol 1, Issue 1 viewed Nov 2006 <http://www.gamestudies.org/0101/eskelinen/>

[12] Hill, R W et al, 2006 'Pedagogically Structured Game-Based Training: Development of the Elect-Bilat Simulation'. Proc. $25^{\text {th }}$ Army Science Conf. 
[13] Kaptelinin, V and Nardi, B.A. 1997 'Activity Theory: Basic Concepts and Applications' viewed Oct 2006 <http://www.acm.org/sigchi/chi97/proceedings/tutorial/bn.htm\#U2>

\section{Further Reading}

Gee P, 2007, Good Video Games and Good Learning

Funge J D, 2007, AI for Computer Games

Natkin S, 2006, Video Games and Interactive Media 